\title{
AN EPIDEMIOLOGICAL SURVEY TO EVALUATE THE AWARENESS OF ANTERIOR TEETH RESTORATIONS IN SOUTH WEST COASTAL POPULATION OF INDIA
}

\author{
Nirupama R1, Mahalaxmi Yelapure ${ }^{2}$, Lakshmi Ramesh ${ }^{3}$
}

${ }_{1}^{1}$ Reader, Department of Prosthodontics and Crown and Bridge, AB Shetty Memorial Institute of Dental Sciences, Mangalore, Nitte (Deemed to be University), Karnataka, India.

2Reader, Department of conservative Dentistry and Endodontics, AB Shetty Memorial Institute of Dental Sciences, Mangalore, Nitte (Deemed to be University), Karnataka, India.

${ }^{3}$ Lecturer, Department of Prosthodontics and Crown and Bridge, AB Shetty Memorial Institute of Dental Sciences, Mangalore, Nitte (Deemed to be University), Karnataka, India.

\section{BACKGROUND}

ABSTRACT

A smile can describe a person's personality. The ideal goal of modern dentistry is to restore the tooth to normal contour, aesthetics, function, comfort, speech and health. Long term loss of teeth especially in the anterior region can lead to undesirable effects such as aesthetic impairment, supra-eruption, change in occlusal contacts, and migration of adjacent teeth which can lead to increased risk of Tempromandibular Disorders (TMDs). Therefore, the awareness and knowledge regarding different dental procedures and dental prostheses for partial edentulousness at individual and community levels can improve oral function. This survey was conducted to assess the awareness of various treatment modalities for anterior teeth restorations in southwest coastal population of India.
\end{abstract}

\section{MATERIALS AND METHODS}

This cross-sectional questionnaire-based survey was conducted on 100 patients visiting the Department of Prosthodontics Outpatient Clinic at A. B. Shetty Memorial Institute of Dental Sciences.

\section{RESULTS}

The maximum cause for loss of teeth for males and females was due to caries. The type of anterior dental restoration mostly u sed by males and females in the age group of 30-45 years and 45-60 years was seen to be removable partial denture prosthesis and implant was the least used. Males were willing for anterior dental restoration mostly for functional purpose whereas females were willing for aesthetics purpose. Population in the urban areas were willing for restorations for aesthetic and functional purpose, peri-urban areas for functional purposes and rural areas for aesthetics purposes.

\section{CONCLUSION}

Awareness helps the patients to have an early replacement of missing teeth. The timely provision of anterior dental restorations helps the patients to achieve better quality of life. Mobile dental clinics, dental camps, and prosthodontic outreach programs would be a possible solution to change attitudes, spread awareness, and extend treatment.

\section{KEY WORDS}

Anterior Tooth Restoration, Awareness, Willingness, Age, Gender, Location.

HOW TO CITE THIS ARTICLE: Nirupama R, Yelapure M, Ramesh L. An epidemiological survey to evaluate the awareness of anterior teeth restorations in south west coastal population of India. J. Evolution Med. Dent. Sci. 2018;7(50):5363-5367, DOI: $10.14260 /$ jemds/2018/1187

\section{BACKGROUND}

A smile can describe a person's personality. The ideal goal of modern dentistry is to restore the tooth to normal contour, aesthetics, function, comfort, speech and health. The dentist provides such restoration, whether removing caries from a tooth or replacing several teeth.

In our competitive modern society, men and women are mindful of their appearance, especially when it comes to facial aesthetics. Therefore, loss of anterior teeth plays an important role in the quality and well-being of an individual at a psychological, biological and social levels.(1)

'Financial or Other Competing Interest': None.

Submission 31-10-2018, Peer Review 24-11-2018,

Acceptance 30-11-2018, Published 10-12-2018.

Corresponding Author:

Dr. Nirupama R,

Reader, Department of Prosthodontics,

AB Shetty Memorial Institute of Dental Sciences,

Deralakatte, Mangalore-575018, Karnataka, India.

E-mail:niru_nidhi@rediffmail.com

DOI: $10.14260 /$ jemds/2018/1187

\section{(c) $(1) \odot$}

Statistics released by the union ministry of health and family welfare show that life expectancy in India has gone up by 5 years, from 62.3 years for males and 63.9 years for females in 2001-2005 to 67.3 years and 69.6 years respectively in 2011-2015.(2)

Long term loss of teeth especially in the anterior region can lead to undesirable effects such as aesthetic impairment, supra-eruption, change in occlusal contacts, migration of adjacent teeth which can lead to increased risk of TMDs.(3)

Therefore, the awareness and knowledge regarding different dental procedures and dental prostheses for partial edentulousness at individual and community levels can improve oral function and more importantly one's selfconfidence and social life with positive psychological impact. This can be brought about by control programs, media or a thorough discussion of all treatment options with a dentist who can truly appreciate a person's desire for rehabilitation.

In developing countries like ours, the awareness among the patients regarding various aesthetics restorative treatment for anterior teeth is not fully understood. This is 
due to the patients being poorly informed about the treatment options available.

This survey was conducted to assess the awareness of various treatment modalities for anterior teeth restorations in south coastal population of India.

\section{MATERIALS AND METHODS}

This cross-sectional questionnaire-based survey was conducted on patients visiting the Department of Prosthodontics Outpatient clinic at A. B. Shetty Memorial Institute of Dental Sciences. The survey included 100 subjects $(n=100)$ based on the knowledge and awareness on various dental restorations and prosthesis for anterior teeth.

Based on previous literature (1) it is observed that the awareness regarding the anterior restorations was approximately $45 \%$. Based on this information the following sample size estimation was done.

$\mathrm{n}=4 \mathrm{p} \mathrm{q}$

$\mathrm{d}^{2}$

$\mathrm{p}=45$

$\mathrm{q}=100-\mathrm{p}(100-45)$

$\mathrm{d}=10$

$\mathrm{n}=4 \times 55 \times 45=99$

$10^{2}$

Therefore, the number of subjects participating in the survey was $100(\mathrm{n}=100)$.

A self-constructed questionnaire based on WHO 2012 Oral Health Survey guidelines containing 33 questions was designed in English language and the data was collected by relevant dental professionals via in -depth interview session.

Questions were designed to evaluate the awareness and knowledge of different types of restorative treatments available for anterior teeth. Gender, age and sociodemographic details of subjects were also recorded.

Based on the questionnaire, the data collected was divided into four groups and three subgroups each-

\section{Group 1: Reason for Loss of Teeth according to:}

(a) Gender (b) Age (c) Location

Group 2: Type of Anterior Restoration used by Subjects according to:

(a) Gender (b) Age (c) Location

Group 3: Willingness for Restoration according to:

(a) Gender (b) Age (c) Location

Group 4: Awareness of Various Restorative Treatment in Anterior Region according to:

(a) Gender (b) Age (c) location

Data were analyzed using IBM SPSS (Statistical package of social sciences) version 24 in terms of frequency and percentage. Chi-square test was utilized to assess significant association between the findings.

\section{RESULTS}

Reasons for loss of teeth according to gender, age and location in terms of number of subjects can be seen in Fig 1.A, Fig 1.B, and Fig 1.C respectively. Type of anterior restorations used by the subjects according to gender, age and location is seen in Fig 2.A, Fig 2.B, and Fig 2.C respectively. Willingness for anterior restoration according to gender, age and location is seen in Table 1.A, Table 1.B and Table 1.C respectively Awareness of various restorative treatments in anterior region according to gender, age and location is seen in Table 2.A, Table 2.B and Table 2.C respectively.

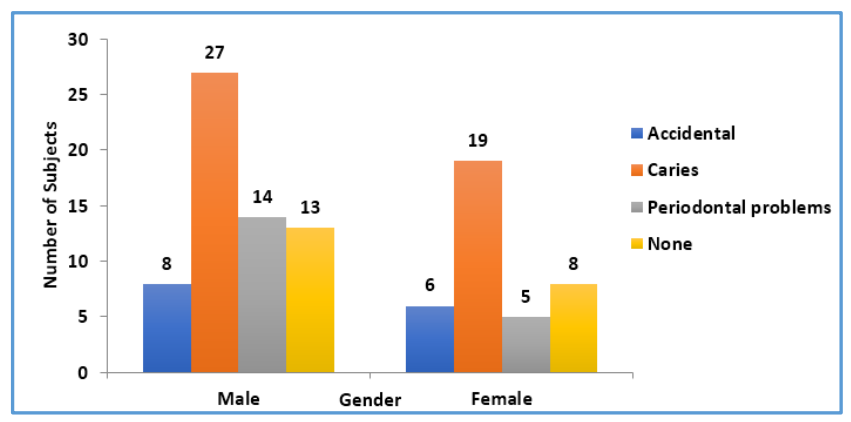

Figure 1A. Reasons for Loss of Teeth according to Gender

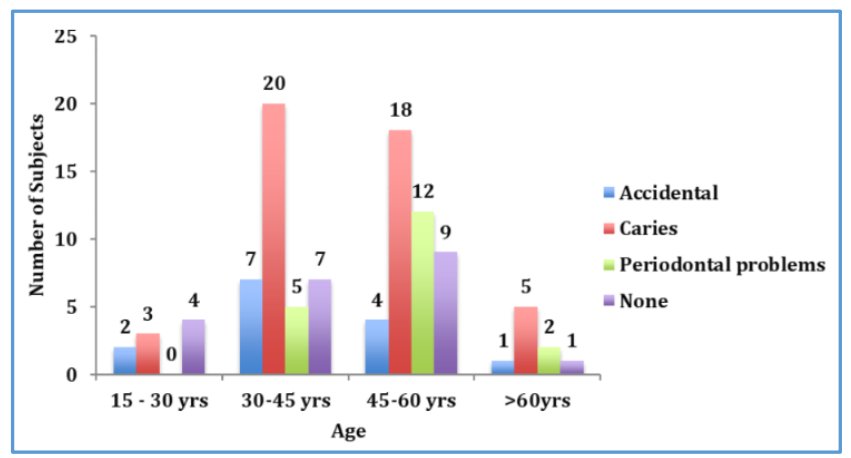

Figure 1B. Reasons for Loss of Teeth according to Age

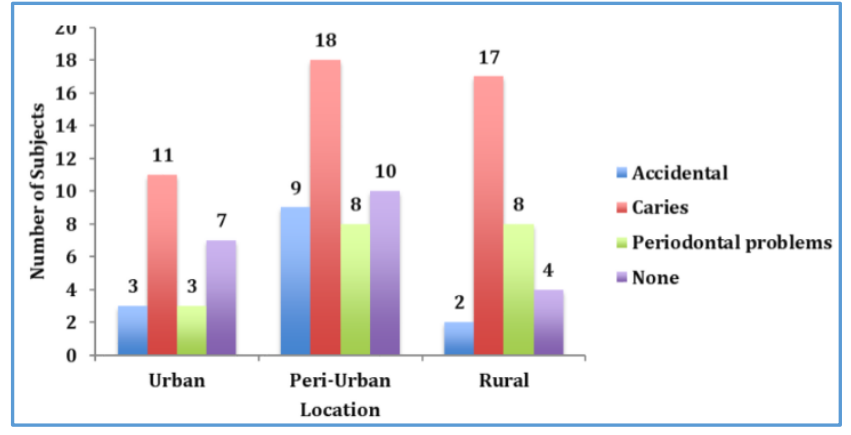

Figure 1C. Reasons for Loss of Teeth according to Location

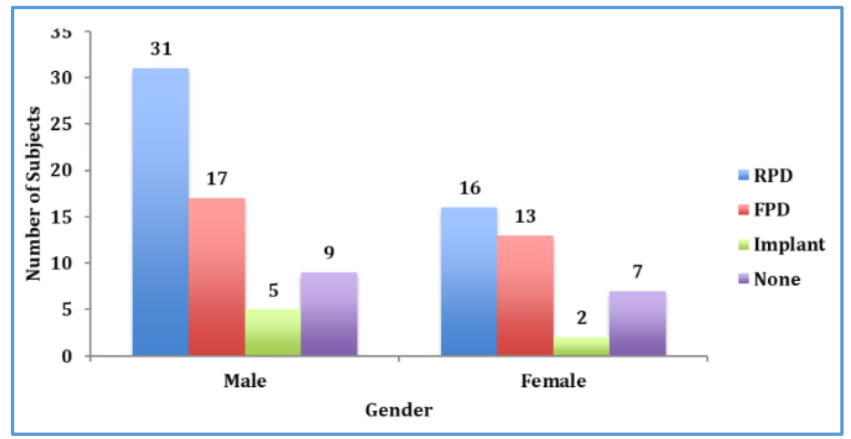

Figure 2 A. Types of Anterior Restorations in Patients according to Gender 


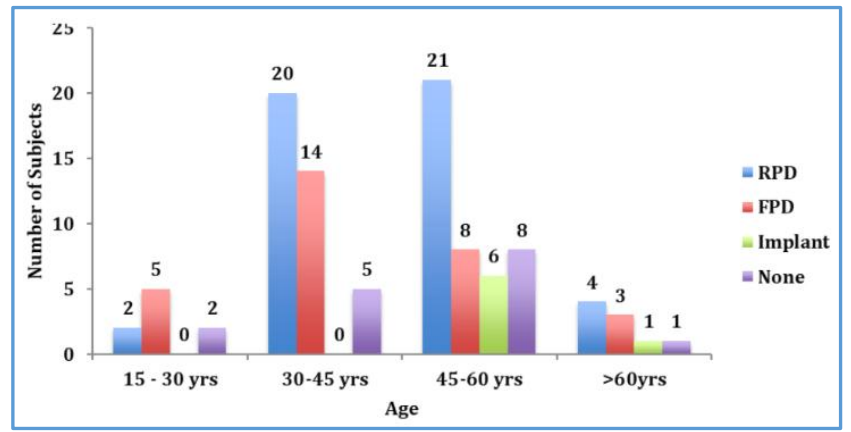

Figure 2 B. Types of Anterior Restorations in Patients according to Age

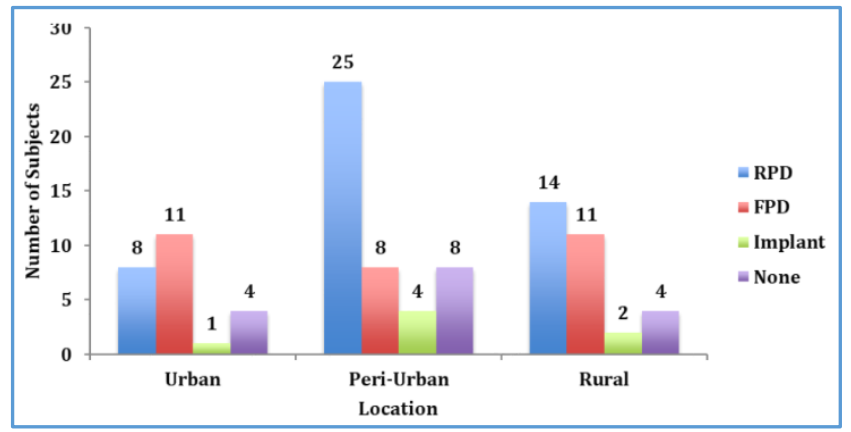

Figure 2 C. Types of Anterior Restorations in Patients according to Location

\begin{tabular}{|c|c|c|c|c|}
\hline & \multicolumn{2}{|c|}{ Males } & \multicolumn{2}{|c|}{ Females } \\
\hline & No. of Subjects & $\%$ & No. of Subjects & $\%$ \\
\hline Esthetic purpose & 15 & 24.2 & 17 & 44.7 \\
\hline Functional purpose & 28 & 45.2 & 7 & 18.4 \\
\hline Esthetic and Functional purposes & 19 & 30.6 & 14 & 36.8 \\
\hline
\end{tabular}

Chi-square value $=8.20$, $\mathrm{p}$-value $=0.02 *{ }^{*} \mathrm{P}<0.05$ statistically significant, $\mathrm{P}>0.05 \mathrm{NS}$.

\begin{tabular}{|c|c|c|c|c|c|c|c|c|}
\hline & \multicolumn{2}{|c|}{$\begin{array}{c}\text { Between } 15 \text { and } 30 \\
\text { Years }\end{array}$} & \multicolumn{2}{|c|}{$\begin{array}{c}\text { Between } 30 \text { and } 45 \\
\text { Years }\end{array}$} & \multicolumn{2}{|c|}{$\begin{array}{c}\text { Between } 45 \text { and } 60 \\
\text { Years }\end{array}$} & \multicolumn{2}{|c|}{$\begin{array}{l}\text { Above } 60 \\
\text { Years }\end{array}$} \\
\hline & $\begin{array}{c}\text { No. of } \\
\text { Subjects }\end{array}$ & $\%$ & $\begin{array}{c}\text { No. of } \\
\text { Subjects }\end{array}$ & $\%$ & $\begin{array}{c}\text { No. of } \\
\text { Subjects }\end{array}$ & & $\begin{array}{c}\text { No. of } \\
\text { Subjects }\end{array}$ & $\%$ \\
\hline Esthetic Purpose & 4 & 44.4 & 14 & 35.9 & 11 & 25.6 & 3 & 33.3 \\
\hline Functional Purpose & 0 & 0.0 & 15 & 38.5 & 18 & 41.9 & 2 & 22.2 \\
\hline $\begin{array}{c}\text { Esthetic and Functional } \\
\text { Purposes }\end{array}$ & 5 & 55.6 & 10 & 25.6 & 14 & 32.6 & 4 & 44.4 \\
\hline
\end{tabular}

p-value $=0.18(\mathrm{NS}) .{ }^{*} \mathrm{P}<0.05$ statistically significant, $\mathrm{P}>0.05$ NS. NS: Non-significant.

\begin{tabular}{|c|c|c|c|c|c|c|}
\hline \multirow{2}{*}{} & \multicolumn{2}{|c|}{ Urban } & \multicolumn{2}{c|}{ Peri-Urban } & \multicolumn{2}{c|}{ Rural } \\
\cline { 2 - 7 } & No. of Subjects & $\mathbf{\%}$ & No. of Subjects & \% & No. of Subjects & \% \\
\hline Esthetic Purpose & 7 & 29.2 & 10 & 22.2 & 15 & 48.4 \\
\hline Functional Purpose & 7 & 29.2 & 18 & 40.0 & 10 & 32.3 \\
\hline Esthetic and Functional Purposes & 10 & 41.7 & 17 & 37.8 & 6 & 19.4 \\
\hline \multicolumn{2}{|r}{} \\
\hline
\end{tabular}

Chi-square value $=7.23, \mathrm{p}$-value $=0.12(\mathrm{NS}) .{ }^{*} \mathrm{P}<0.05$ statistically significant, $\mathrm{P}>0.05 \mathrm{NS}$. NS: Non-significant

\begin{tabular}{|c|c|c|c|c|}
\hline \multirow{2}{*}{} & \multicolumn{2}{|c|}{ Males } & \multicolumn{2}{c|}{ Females } \\
\cline { 2 - 5 } & No. of Subjects & \% & No. of Subjects & 81.6 \\
\hline Aware & 54 & 87.1 & 31 & 18.4 \\
\hline Unaware & 8 & 12.9 & 7 & Gender \\
\hline
\end{tabular}

Chi-square value $=0.56, \mathrm{p}$-value $=0.45(\mathrm{NS}) .{ }^{*} \mathrm{P}<0.05$ statistically significant, $\mathrm{P}>0.05 \mathrm{NS}$. NS: Non-significant

\begin{tabular}{|c|c|c|c|c|c|c|c|c|}
\hline \multirow{2}{*}{} & \multicolumn{2}{|c|}{$\begin{array}{c}\text { Between 15 and 30 } \\
\text { Years }\end{array}$} & $\begin{array}{c}\text { Between 30 and 45 } \\
\text { Years }\end{array}$ & \multicolumn{2}{c|}{$\begin{array}{c}\text { Between 45 and 60 } \\
\text { Years }\end{array}$} & \multicolumn{2}{c|}{$\begin{array}{c}\text { Above 60 } \\
\text { Years }\end{array}$} \\
\cline { 2 - 9 } & $\begin{array}{c}\text { No. of } \\
\text { Subjects }\end{array}$ & $\%$ & $\begin{array}{c}\text { No. of } \\
\text { Subjects }\end{array}$ & $\%$ & $\begin{array}{c}\text { No. of } \\
\text { Subjects }\end{array}$ & $\begin{array}{c}\text { No. of } \\
\text { Subjects }\end{array}$ & $\begin{array}{c}\text { \% } \\
7\end{array}$ \\
\hline Aware & 8 & 88.9 & 31 & 79.5 & 39 & 90.7 & 2 & 77.8 \\
\hline Unaware & 1 & 11.1 & 8 & 20.5 & 4 & 9.3 & 7 & 22.2 \\
\hline
\end{tabular}

$\mathrm{p}$-value $=0.44$ (NS). ${ }^{*} \mathrm{P}<0.05$ statistically significant, $\mathrm{P}>0.05$ NS. NS: Non-significant 


\begin{tabular}{|c|c|c|c|c|c|c|}
\hline \multirow{2}{*}{} & \multicolumn{2}{|c|}{ Urban } & \multicolumn{2}{c|}{ Peri-Urban } & \multicolumn{2}{c|}{ Rural } \\
\cline { 2 - 7 } & No. of Subjects & \% & No. of Subjects & \% & No. of Subjects & \% \\
\hline Aware & 21 & 87.5 & 39 & 86.7 & 25 & 80.6 \\
\hline Unaware & 3 & 12.5 & 6 & 13.3 & 6 & 19.4 \\
\hline Table 2C. Awareness of Various Restorative Treatments in the Anterior Region according to Location \\
\hline
\end{tabular}

p-value $=0.77$ (NS). ${ }^{*} \mathrm{P}<0.05$ statistically significant, $\mathrm{P}>0.05$ NS. NS: Non-significant

\section{DISCUSSION}

Dental health has an influence on the general health status. Loss of teeth can have impact on individuals not only psychologically but also biologically and at social levels. It is therefore necessary to replace missing tooth/ teeth as early as possible to retard the deteriorating oral and general health status. (4)

Patient's awareness and knowledge about dental prosthesis is one of the most important factors in selection of any particular dental prosthesis. There are many ways to determine patient's knowledge and awareness.(5)

In India epidemiological data on patient awareness of different anterior restorative modalities is very limited. An attempt was made to find out the awareness of anterior teeth restorations among patients reporting to A. B. Shetty Memorial Institute of Dental Sciences which has a patient input to the OPD from as far as north coastal Karnataka to south coastal regions of Kerala.

Most of the subjects belonged to the age group 45-60 years which is similar to the finding in a survey by Shreya Gupta et al where $42.1 \%$ of patients were within the same age group of 41-50 years. $\left.{ }^{6}\right)$

In the present study it was seen that the majority of subjects that is $51.3 \%$ within the age group $30-45$ years presented tooth loss due to caries which is a finding close to the finding of a previous study by Baelum. $\mathrm{V}$ et al where it was seen that $55 \%-84 \%$ within the age group $30-49$ years presented loss of teeth due to caries.(7)

It was seen, in this survey that the main cause of loss of teeth was due to caries which is similar to the finding in a study by Spalj et al which showed over $50 \%$ cases had loss of teeth due to dental caries. (8)

The study also revealed that loss of teeth due to periodontal problems was higher in the age group of 45-60 years which is also in accordance to the study by Baelum. $V$ et al where $24 \%$ of subjects had tooth loss due to periodontal problems which was more prevalent in the oldest age group.(7)

Majority of the women in this survey that is around $42.1 \%$ subjects had removable partial denture prosthesis which was similar to the findings seen in the study by Abiodun O.A et al where majority of women that is around $35.5 \%$ had removable partial denture prosthesis. ${ }^{(9)}$

This survey also showed that majority of subjects within the age group 30-45 years and $45-60$ years had removable partial denture prosthesis which is similar to the finding seen in the study by Catherine Hayes where the number of removable partial denture prosthesis increased as the age of the patients increased.(10)

The study also showed that there was varied willingness for anterior restoration. According to gender, the study showed that highest number of females $44.7 \%$ required replacement for aesthetic purpose. According to age, it was noted that age group $15-30$ years around $55.6 \%$ were willing for replacement for aesthetic and functional purpose. According to demographics, the urban population showed highest willingness of $47.7 \%$ for both aesthetic and functional replacements.

According to this study $87.1 \%$ male patients were aware of anterior restoration compared to $81.6 \%$ females which was in contrast to the finding seen in a study by Al Fawaaz where it was reported that about $18 \%$ Saudi female patients were aware of dental restoration for missing teeth compared to $9 \%$ in a group of males.(11,12)

\section{CONCLUSION}

Within the limitation of this study, the following conclusions can be made

1. The most common cause for loss of teeth for males and females was due to caries. Loss of teeth due to caries was highest in the age groups 30-45 years and 45-60 years. Also, caries was the highest cause of tooth loss in urban, peri-urban and rural regions.

2. The type of anterior dental restoration mostly used by males and females in the age group of 30-45 years and 45-60 years was removable partial denture prosthesis and implant was the least used. The type of anterior dental restoration mostly in use in the urban, peri-urban and rural areas was seen to be removable partial denture prosthesis.

3. Males were willing for anterior dental restoration mostly for functional purpose whereas females were willing for aesthetics purpose. Age groups 15-30 years were willing for dental restorations for aesthetic and functional purpose, 30-45 years for functional purposes, 45-60 years for functional purposes, above 60 years for both aesthetics and functional purposes. Population in the urban areas were willing for restorations for aesthetic and functional purpose, peri-urban areas for functional purposes and rural areas for aesthetics purposes.

4. Males were more aware of anterior dental restorations compared to females. Awareness was seen to be highest within the age group 45-60 years and in urban population.

Lack of awareness of different prosthodontic treatment options among people living in rural villages prevents them from availing treatment even though there are many government-setups that offer treatment free of cost.

Awareness thus helps the patients to have an early replacement of missing teeth. The timely provision of anterior dental restorations helps the patients to achieve better quality of life.

Mobile dental clinics, dental camps, and prosthodontic outreach programs would be a possible solution to change attitudes, spread awareness, and extend treatment. 


\section{REFERENCES}

[1] Sivesh S. Awareness and attitudes of patients towards prosthetic rehabilitation of missing teeth at Saveetha Dental College and hospital. Int J Sci Dev \& Res 2017;2(4):414-21.

[2] https://currentaffairs.gktoday.in/tags/life-expectancy

[3] Abdurahiman VT, Khader AM, Jolly SJ. Frequency of partial edentulism and awareness to restore the same: a cross sectional study in the age group of 18-25 years among Kerala student population. J Indian Prosthodont Soc 2013;13(4):461-5.

[4] Al-Quran FA, Al-Ghalayini RF, Al-Zu'bi BN. Single-tooth replacement: factors affecting different prosthetic treatment modalities. BMC Oral Health 2011;11:34.

[5] Rustemeyer J, Bremerich A. Patients' knowledge and expectations regarding dental implants: assessment by questionnaire. Int J Oral Maxillofac Surg 2007;36(9):814-7.

[6] Gupta S, Mantri SS, Bhasin A. Knowledge and attitude towards prosthodontic rehabilitation and utilization of dental services by Central India Population of Jabalpur city, India. Annals of Medical and Health Sciences Research 2018;8(2):12-5.
[7] Baelum V, Fejerskov 0. Tooth loss as related to dental caries and periodontal breakdown in adult Tanzanians. Community Dent Oral Epidemiol 1986;14(6):353-7.

[8] Spalj S, Plancak D, Jurić $\mathrm{H}$, et al. Reasons for extraction of permanent teeth in urban and rural populations of Croatia. Coll Antropol 2004;28(2):833-9.

[9] Arigbede AC, Taiwo JO. Pattern of Demand for Removable Acrylic Partial Denture (RPD) in the city of Port Harcourt, Nigeria, The Nigerian Health Journal 2011;11(2):47-50.

[10] Hayes C. The quality of the majority of removable partial dentures worn in the United States is remarkably low. J Evid-Based Dent Pract 2003;3(2):82-3.

[11] Al-Fawaz AA. Needs and demands for dental treatment among Saudi female patients in the dental school in Riyadh. Saudi Dent J 1999;11:120-3.

[12] Menezes M, Aras M. Prosthodontic awareness and fulfilment of prosthodontic need in rural areas of Goa. J Indian Dent Ass 2009;(11):368-73. 